\title{
Self-reported Sleep Duration and Subclinical Atherosclerosis in a General Population of Japanese Men
}

\author{
Sentaro Suzuki ${ }^{1}$, Hisatomi Arima ${ }^{1,2,3}$, Soichiro Miyazaki ${ }^{4}$, Akira Fujiyoshi ${ }^{1}$, Aya Kadota ${ }^{1,3}$, \\ Naoyuki Takashima ${ }^{1}$, Takashi Hisamatsu ${ }^{1,3,5}$, Sayaka Kadowaki ${ }^{1}$, Maryam Zaid ${ }^{1,3}$, Sayuki Torii ${ }^{1,6}$, \\ Minoru Horie $^{6}$, Kiyoshi Murata ${ }^{7}$, Katsuyuki Miura ${ }^{1,3}$, Hirotsugu Ueshima ${ }^{1,3}$, for the SESSA Research Group \\ ${ }^{1}$ Department of Public Health, Shiga University of Medical Science, Otsu Japan \\ ${ }^{2}$ Department of Preventive Medicine and Public Health, Faculty of Medicine, Fukuoka University, Fukuoka Japan \\ ${ }^{3}$ Center for Epidemiologic Research in Asia, Shiga University of Medical Science, Otsu Japan \\ ${ }^{4}$ Research Institute of Life and Health Sciences, Chubu University, Nagoya Japan \\ ${ }^{5}$ Department of Environmental Medicine and Public Health, Faculty of Medicine, Shimane University, Izumo, Japan \\ ${ }^{6}$ Department of Cardiovascular and Respiratory Medicine, Shiga University of Medical Science, Otsu, Japan \\ ${ }^{7}$ Department of Radiology, Shiga University of Medical Science, Otsu, Japan
}

Aim: There are few data regarding associations between sleep duration and subclinical atherosclerosis in Japan. The aim of this study was to evaluate associations of self-reported sleep duration with calcification in the coronary arteries (CAC) and carotid intima media thickness (IMT) in Japanese men. Methods: This was a cross-sectional survey of 1093 randomly selected men from Kusatsu City, Japan. Average sleep duration on weekdays was estimated through questionnaire; CAC by computed tomography; and carotid IMT by ultrasonography.

Results: The prevalence of CAC was $50.0 \%$ for participants with sleep duration $<5.5 \mathrm{~h}, 43.9 \%$ with 5.5-6.4 h, 50.0\% with $6.5-7.4 \mathrm{~h}, 49.3 \%$ with $7.5-8.4 \mathrm{~h}$, and $62.5 \%$ with $\geq 8.5 \mathrm{~h}$. In univariate analysis, participants with sleep duration $\geq 8.5 \mathrm{~h}$ had significantly higher prevalence of CAC than those with $6.5-7.4 \mathrm{~h}(p=0.043)$. After adjustment for age and other risk factors, however, the association was not significant $(p=0.776)$. The average IMT was $0.85 \mathrm{~mm}$ for participants with sleep duration $<5.5 \mathrm{~h}, 0.83 \mathrm{~mm}$ with $5.5-6.4 \mathrm{~h}, 0.85 \mathrm{~mm}$ with $6.5-7.4 \mathrm{~h}, 0.88 \mathrm{~mm}$ with $7.5-8.4 \mathrm{~h}$, and $0.90 \mathrm{~mm}$ with $\geq 8.5 \mathrm{~h}$. None of the differences in IMT observed in crude or multivariableadjusted analyses was significant (all $p>0.1$ ).

Conclusion: Self-reported sleep duration was not associated with increased CAC or carotid IMT in a general population of Japanese men.

Key words: Sleep duration, Coronary artery calcification, Carotid intima media thickness, Epidemiology, Cardiovascular risk

\section{Introduction}

Cardiovascular disease is one of the leading causes of premature death in Japan and worldwide ${ }^{1-3)}$. Although recent decades have seen reductions in the age-adjusted incidence rates of coronary heart disease and stroke in Japan, the actual number of events are

Address for correspondence: Hisatomi Arima, Department of Public Health, Shiga University of Medical Science, Seta

Tsukinowa-cho, Otsu City, Shiga, 520-2192, Japan

E-mail: arima@belle.shiga-med.ac.jp

Received: March 14, 2017

Accepted for publication: June 7, 2017 expected to increase because of an aging population ${ }^{4,5)}$. Strategies based on better knowledge of cardiovascular risk factors are needed to effectively prevent cardiovascular events in Japan.

Several observational studies have investigated the link between sleep duration and incidence of or mortality due to cardiovascular disease. Some have suggested a U-shaped association, i.e., increased risk in individuals with short sleep duration as well as those with long sleep duration ${ }^{6-12}$. Possible mechanisms underlying the U-shaped association include elevated blood pressure ${ }^{13)}$, impaired glucose tolerance ${ }^{14)}$, and increased inflammation ${ }^{15)}$ in those with insufficient 
sleep and raised inflammatory markers in those with long sleep duration ${ }^{16)}$. Observational studies have also reported an association between sleep duration and subclinical atherosclerosis of coronary or carotid arteries ${ }^{17-24)}$, which has been shown to be an important intermediate marker of cardiovascular disease ${ }^{25,26)}$. Some studies reported comparable associations between men and women (SUMSUNG) while others reported the relationship in male participants only (CARDIA IMT). However, current evidence is derived mostly from studies of Western populations; the extent to which these data are applicable to Asian populations, including the Japanese, is uncertain.

\section{Aim}

The aim of this study was to investigate associations of self-reported sleep duration with coronary arteries calcification (CAC) and carotid intima media thickness (IMT) among Japanese men.

\section{Methods}

\section{Study Design and Participants}

SESSA (Shiga Epidemiological Study of Subclinical Atherosclerosis) is an epidemiological study of men randomly selected from the general population of a Japanese city, details of which have previously been described $^{27)}$. In brief, from May 2006 to March 2008, 1094 community-dwelling men aged 40-79 years were selected based on an age-stratified random sample from the Basic Residents' Register of Kusatsu City and received comprehensive physical examinations. After exclusion of a participant without information on sleep duration, a total of 1093 men were included in the present cross-sectional analysis of CAC. After further exclusion of 33 men without information on carotid ultrasound, a total of 1060 men were included in the analysis of carotid IMT. The study was approved by the Institutional Review Board of Shiga University of Medical Science (No. 17-19, 17-83); all participants provided written informed consent.

\section{Sleep Duration}

At the baseline examination, information on average sleep duration on weekdays in the 30 days prior to enrolment was obtained using a questionnaire and confirmed by trained staff. Five participant groups defined by the self-reported sleep duration $(<5.5,5.5-6.4$, $6.5-7.4,7.5-8.4$, and $\geq 8.5 \mathrm{~h}$ per day) were used in the present analysis.

\section{Other Risk Factors}

A self-administered questionnaire was used to obtain information on demography, smoking habits (never, past, and current), alcohol drinking (types of alcohol, frequency, quantity), physical activity, and use of medication(s) for hypertension, dyslipidemia, diabetes mellitus, and sleep disorder. Regular exercise was defined as sports or other forms of exertion at least once a week. Participants with depressive symptoms were defined as those who had the Center for Epidemiologic Studies Depression Scale (CES-D) score $\geq 16^{28)}$. Weight and height were measured to calculate body mass index (BMI). Blood pressure was measured using an automated sphygmomanometer (BP-8800; Omron Colin, Tokyo, Japan) with the patient in a seated position after a 5-min rest; the mean of two measurements was used as the final value. Venous blood was drawn after a 12-h fast and centrifuged soon after coagulation; plasma glucose levels were measured from sodium fluoride-treated plasma using a hexokinase glucose-6phosphate-dehydrogenase enzymatic assay; and hemoglobin A1c (HbA1c) levels were measured using a latex agglutination inhibition assay as per Japan Diabetes Society (JDS) methods and converted into National Glycohemoglobin Standardization Program (NGSP) values using the following formula: HbA1c $(\mathrm{NGSP})(\%)=1.02 \times \mathrm{HbA1c}(\mathrm{JDS})(\%)+0.25^{29)}$. The concentration of standard lipids, including total cholesterol, was measured using enzymatic methods; highdensity lipoprotein (HDL) cholesterol was measured after heparin-calcium precipitation. Lipid measurements were standardized per Center for Disease Control and Prevention/Cholesterol Reference Method Laboratory Network (CDC/CRMLN) guidelines ${ }^{30)}$. Participants with regular exercise were defined as those who regularly exercised $\geq 1 \mathrm{~h} /$ week.

\section{Coronary Artery Calcification}

Detailed procedures for CAC measurement have previously been described ${ }^{31)}$. CAC was assessed by either electron-beam computed tomography (EBCT) $(n=762,69.7 \%)$ using a C-150 scanner (Imatron, South San Francisco, CA, USA), or 16-channel multidetector-row CT (MDCT) $(n=331)$ using an Aquilion scanner (Toshiba, Tokyo, Japan). Images were obtained from the level of the aortic root through the heart in 3-mm slices with a scan time of $100 \mathrm{~ms}$ (EBCT) or $320 \mathrm{~ms}$ (MDCT). Images were acquired at $70 \%$ of the cardiac cycle using electrocardiogram triggering during a single breath-hold. Quantification of CAC was performed using a DICOM workstation and AccuImage software (AccuImage Diagnostics, South San Francisco, CA, USA). CAC was considered present if there were a minimum of three contiguous pixels (each with area $1 \mathrm{~mm}^{2}$ ) with a density of $\geq 130$ Hounsfield units (HU). A region of interest was 
placed around each high-density lesion in the epicardial coronary arteries. The peak density and area of the individual coronary calcifications were measured and the CAC score calculated per the Agatston method ${ }^{32)}$. All CT images were read by one physician, trained in CT reading at the Cardiovascular Institute of the University of Pittsburgh, who was blinded to participants' demographics. The protocol described above was adopted from a separate cohort study performed by our research group ${ }^{33)}$, which showed high inter-rater reliability (intraclass correlation coefficient 0.98$)^{34)}$. In the present analysis, the presence of CAC was defined as a CAC score $\geq 10^{35)}$, but sensitivity analyses were conducted using a definition of a CAC score $>0$.

\section{Intimal Media Thickness of the Carotid Artery}

The IMT measurement protocol has previously been described ${ }^{36)}$. Using a 7.5 MHz probe (Xario-660A; Toshiba Medical Systems, Tokyo, Japan), detailed $\mathrm{B}$-mode images of the right and left common carotid artery (CCA), common carotid bifurcation, and internal carotid artery (ICA) were obtained with a standardized method established by the Ultrasound Research Laboratory of the University of Pittsburgh ${ }^{37)}$. Images from the following segments were digitized: near and far walls of the distal CCA $(1 \mathrm{~cm}$ proximal to the carotid bulb); far wall of the bulb; and a $1-\mathrm{cm}$ area of the far wall of the ICA (a total of four locations per side). The carotid IMT was traced with an automatic image-reading program (AMS; Chalmers University of Technology, Gothenburg, Sweden). In this study, the mean carotid IMT comprised the mean of all average readings across the eight locations from the CCA, bulb, and $\mathrm{ICA}^{36)}$.

\section{Statistical Analysis}

Each participant characteristic was described as a mean (standard deviation [SD]) or median (interquartile range $[\mathrm{IQR}]$ ) for continuous variables and a percentage for categorical variables. Differences were evaluated using the Kruskal-Wallis or chi-squared test, as appropriate. Crude and multivariable-adjusted logistic regression models were used to estimate odds ratios (OR) and 95\% confidence intervals (CI) for the presence of CAC. Participants with a sleep duration of 6.5-7.4 h were used as reference, in accordance with findings from previous studies ${ }^{6-12}$. Analysis of covariance (ANCOVA) was used to test for associations between sleep duration and mean carotid IMT. The multivariable-adjusted models included confounding factors of age, BMI, smoking status, regular exercise, alcohol consumption, and type of CT (model 1). We also conducted multivariable analysis with further adjustment for possible mediators (i.e., established cardiovascular risk factors that have been shown to be associated with sleep duration) including systolic blood pressure, total cholesterol, HDL cholesterol, HbA1c, and medication status ${ }^{38,39)}$ (model 2). Difference in associations between subgroups (age group, BMI group, smoking status, alcohol consumption, working status, use of sleeping pills, or presence of depressive symptoms) were assessed by adding interaction terms to the model. Analyses were performed using SAS version 9.4 (SAS Institute, Cary, NC, USA). Two-tailed $p$ values $<0.05$ were considered significant.

\section{Results}

Participant characteristics are shown in Table $\mathbf{1 .}$ Participants with longer sleep durations were older, had lower BMIs, and higher systolic blood pressures than those with shorter sleep durations.

The number of participants with CAC was 538 (49.2\%). The prevalence was 50.0\%, 43.9\%, 50.0\%, $49.3 \%$, and $62.5 \%$ for individuals with sleep durations of $<5.5,5.5-6.4,6.5-7.4,7.5-8.4$, and $\geq 8.5$ $\mathrm{h}$, respectively (Table 2 ). In a crude analysis, individuals with sleep duration $\geq 8.5 \mathrm{~h}$ had significantly higher CAC prevalence (OR 1.67; 95\% CI, 1.02-2.73; $p=$ 0.043 ) than those with $6.5-7.4 \mathrm{~h}$. However, the difference was not statistically significant after adjustment for age (OR $1.01 ; 95 \% \mathrm{CI}, 0.60-1.72 ; p=0.961$ ) or for age and other cardiovascular risk factors (OR 1.08; 95\% CI, $0.63-1.86 ; p=0.776$ ). Findings were similar when subjects with stroke and/or myocardial infarction were excluded from the analysis (Supplementary Table 1) or when a CAC score of $>0$ was used as threshold (Supplementary Table 2). There were no clear differences in association between sleep duration and CAC when participants were further stratified by age group, BMI group, smoking status, alcohol consumption, employment status, use of sleeping pills, or presence of depressive symptoms (all $p>0.2$ for heterogeneity; Supplementary Table 3). There were also comparable associations between sleep duration and CAC between the 762 participants who were assessed using EBCT and the 331 assessed using MDCT ( $p=$ 0.289 for heterogeneity).

The overall mean carotid IMT was $0.86 \mathrm{~mm}$; mean values were $0.85 \mathrm{~mm}, 0.83 \mathrm{~mm}, 0.85 \mathrm{~mm}, 0.88$ $\mathrm{mm}$, and $0.90 \mathrm{~mm}$ for individuals with sleep durations of $<5.5,5.5-6.4,6.5-7.4,7.5-8.4$, and $\geq 8.5$ $\mathrm{h}$, respectively (Table 3). There were no significant differences among the five groups (all $p>0.1$ ). There were also no important associations between sleep duration and mean carotid IMT after adjustment for age or after adjustment for age and other cardiovascular risk factors (all $p>0.1)$. There were no clear differ- 
Table 1. Characteristics of male participants enrolled in SESSA $(2006-2008)$ stratified by sleep duration $(n=1093)$

\begin{tabular}{|c|c|c|c|c|c|c|c|}
\hline & overall & \multicolumn{5}{|c|}{ Sleep duration (hours) } & \\
\hline Participant characteristic & $(n=1093)$ & $(n=118)$ & $(n=278)$ & $(n=394)$ & $(n=223)$ & $(n=80)$ & $p^{*}$ \\
\hline Age (years) & $64.1(9.9)$ & $62.3(11.6)$ & $61.5(10.8)$ & $63.7(9.4)$ & $66.7(7.9)$ & $69.9(7.5)$ & $<0.0001$ \\
\hline Body mass index $\left(\mathrm{kg} / \mathrm{m}^{2}\right)$ & $23.6(3.0)$ & $23.7(2.9)$ & $24.0(2.9)$ & $23.7(2.9)$ & $23.4(3.0)$ & $22.3(3.3)$ & 0.002 \\
\hline Total cholesterol (mg/dL) & $208.1(33.7)$ & $207.8(32.0)$ & $209.2(34.7)$ & $207.3(31.6)$ & $210.1(35.5)$ & $203.7(37.6)$ & 0.781 \\
\hline LDL cholesterol $(\mathrm{mg} / \mathrm{dL})^{*}$ & $124.7(31.6)$ & $123.7(31.9)$ & $125.0(31.5)$ & $124.4(29.4)$ & $127.2(33.9)$ & $120.1(34.9)$ & 0.638 \\
\hline HDL cholesterol (mg/dL) & $58.6(16.9)$ & $58.6(17.0)$ & $59.5(17.2)$ & $58.2(16.4)$ & $57.9(17.0)$ & $59.8(18.0)$ & 0.767 \\
\hline Triglyceride (mg/dL) & $106(77-150)$ & $111.5(78-157)$ & $106(77-149)$ & $106(77-153)$ & $108(75-147)$ & $96.5(76.5-142.5)$ & 0.853 \\
\hline Blood glucose (mg/dL) & $102.7(21.2)$ & $101.7(21.6)$ & $102.2(19.3)$ & $102.8(21.4)$ & $104.8(24.0)$ & $100.3(17.0)$ & 0.657 \\
\hline Alcohol consumption (g/day) & $23.1(27.3)$ & $26.5(33.3)$ & $23.5(27.3)$ & $21.6(25.5)$ & $23.1(25.9)$ & $24.5(29.3)$ & 0.943 \\
\hline Medication for hypertension & $(28.8)$ & $(30.5)$ & $(27.0)$ & $(27.7)$ & $(28.7)$ & $(38.8)$ & 0.317 \\
\hline Medication for dyslipidemia & $(11.3)$ & $(13.7)$ & $(12.2)$ & $(10.9)$ & $(9.5)$ & $(12.7)$ & 0.773 \\
\hline Medication for diabetes & $(10.3)$ & $(11.0)$ & $(7.9)$ & $(11.2)$ & (12.6) & $(6.3)$ & 0.312 \\
\hline Medication for sleep & $(5.5)$ & (7.6) & (7.6) & $(5.3)$ & $(3.1)$ & $(2.5)$ & 0.131 \\
\hline Depressive symptoms $^{\dagger}$ & (7.9) & $(11.0)$ & $(13.3)$ & $(4.8)$ & (7.6) & $(0.0)$ & $<0.0001$ \\
\hline
\end{tabular}

Values are expressed as mean (standard deviation), median (interquartile range) or (\%). ${ }^{*}$ Calculated by the formula of Friedwald $e t$ al. ${ }^{\dagger}$ Center for Epidemiologic Studies Depression Scale score $\geq 16^{*} P$ values were estimated using Kruskal-Willis test for continuous and $\chi^{2}$ test for categorical variables. IQR: interquartile range; LDL: low-density lipoprotein; HbA1c: hemoglobin A1c; HDL: high-density lipoprotein; SD: standard deviation; SESSA: Shiga Epidemiological Study of Subclinical Atherosclerosis

ence in associations between sleep duration and carotid IMT among subgroups ( $p>0.05$ for heterogeneity; Supplementary Table 4).

\section{Discussion}

To our knowledge, this is the first study to investigate possible associations between sleep duration and subclinical atherosclerosis in a general Japanese population. Although participants with sleep duration $\geq 8.5$ $\mathrm{h}$ were more likely to have CAC, the association disappeared after adjustment for age. There were also no clear associations between sleep duration and carotid IMT.

Previous studies investigating these associations have shown inconsistent results ${ }^{40)}$ and are summarized in Supplementary Tables 5 and 6. The Kangbuk Samsung Health Study $(n=29$ 203, South Korea) reported a U-shaped association ${ }^{23)}$, whereas the Study of Women's Health Across the Nation (SWAN; $n=$ 512, female only, United States [USA]) demonstrated no clear association ${ }^{17)}$, as did the Heart Strategies Concentrating on Risk Evaluation (HeartSCORE) study $(n=195 \text {, USA })^{22)}$. The Coronary Artery Risk
Development in Young Adults (CARDIA) study ( $n=$ 495, USA) found increased CAC prevalence among participants with short sleep duration measured by actigraphy, but no association when sleep duration was self-reported ${ }^{18)}$. Heterogeneity between studies may be attributable to differences in study design, participant characteristics, method of assessment of sleep duration (self-reported or objective), or definitions of CAC used.

Several observational studies in Western populations have reported higher carotid IMT among participants with short or long sleep duration, or both. The Study of Health in Pomerania (SHIPS; $n=2437$, Germany) found a higher carotid IMT among participants with sleep duration of $<5 \mathrm{~h}$ and $>9 \mathrm{~h}^{19)}$. The Buffalo Cardio-Metabolic Occupational Police Stress study $(n=257$, USA) also demonstrated a U-shaped association between carotid IMT and sleep duration measured by actigraphy, though this was not present when sleep duration was self-reported ${ }^{20)}$. The CARDIA study found increased carotid IMT in male participants with longer objective sleep duration, but not in female participants ${ }^{21)}$. Although much more limited evidence is available for Asian populations, Abe et al. 
Table 2. Prevalence and odds ratio of coronary artery calcification* among male participants enrolled in SESSA (2006-2008) stratified by sleep duration $(n=1093)$

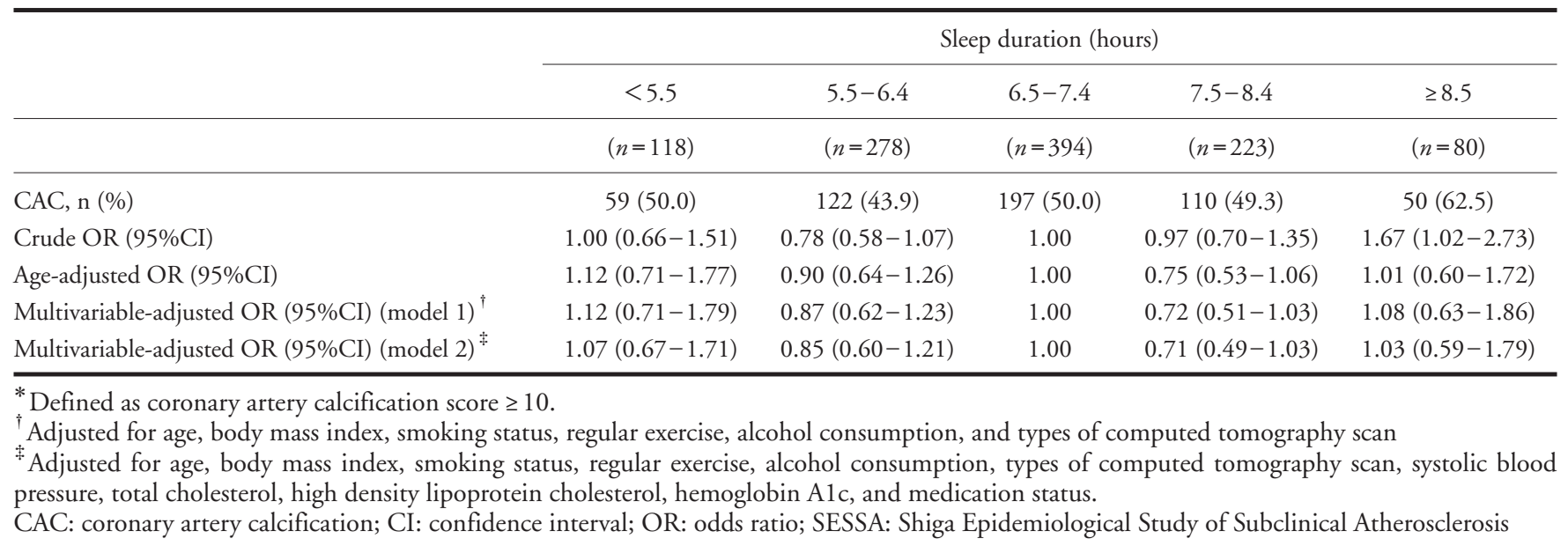

( $n=2498$, Japan) found increased incidence of carotid artery atherosclerosis among people with long sleep duration $(\geq 7 \mathrm{~h})^{24)}$. Given the equivocal results of our own study, further observation of Asian populations is needed to confirm the association between sleep duration and carotid IMT.

In contrast to the studies described above, associations between sleep duration and cardiovascular disease incidence and mortality are well described ${ }^{6-12)}$. The variability may be due to differences in study design, as most studies of subclinical atherosclerosis are cross-sectional, while a most cohort studies for clinical outcomes are prospective. In fact, there has been a prospective study that demonstrated a positive association between sleep duration and progression of $\mathrm{CAC}^{18)}$. Further prospective investigation of sleep duration and subclinical atherosclerosis would provide a better understanding of possible associations with cardiovascular disease.

This study had several limitations. First, the crosssectional design meant that longitudinal associations between sleep duration and atherosclerosis could not be ascertained from the data collected. Although sleep duration can be a cause as well as a consequence of atherosclerosis, a very limited number of prospective studies have investigated CAC progression. We believe the findings from this cross-sectional study, which reported the link between sleep duration and CAC in Japan for the first time, still add some epidemiological evidence to current knowledge in this area. Second, the number of subjects is somewhat small in some groups defined by sleep duration. However, this study had $80 \%$ power to detect clinically significant differences in the outcomes ( $\geq 36 \%$ relative increase in CAC and $\geq 0.07 \mathrm{~mm}$ increase in carotid IMT). In addition, estimates of sleep duration obtained through self- reported questionnaires may be limited in their accuracy, which may have biased the results to null hypothesis, and all participants were men, which may limit the generalizability of findings to women or other ethnicities.

\section{Conclusion}

Self-reported sleep duration was not associated with calcification of the coronary arteries or increased carotid intima media thickness in a general population of Japanese men.

\section{Acknowledgments}

\section{Members of the SESSA Research Group.}

Chairperson: Hirotsugu Ueshima (Center for Epidemiologic Research in Asia, Department of Public Health, Shiga University of Medical Science, Otsu, Shiga).

Co-chairperson: Katsuyuki Miura (Department of Public Health, Shiga University of Medical Science, Otsu, Shiga).

Research members: Minoru Horie, Yasutaka Nakano, Takashi Yamamoto (Department of Cardiovascular and Respiratory Medicine, Shiga University of Medical Science, Otsu, Shiga), Emiko Ogawa (Health Administration Center, Shiga University of Medical Science, Otsu, Shiga), Hiroshi Maegawa, Itsuko Miyazawa (Division of Endocrinology and Metabolism, Department of Medicine, Shiga University of Medical Science, Otsu, Shiga), Kiyoshi Murata (Department of Radiology, Shiga University of Medical Science, Otsu, Shiga), Kenichi Mitsunami (Shiga University of Medical Science, Otsu, Shiga), Kazuhiko Nozaki (Department of Neurosurgery, Shiga University of 
Table 3. Mean IMT among male participants enrolled in SESSA (2006-2008), stratified by sleep duration $(n=1060)$

\begin{tabular}{|c|c|c|c|c|c|}
\hline & \multicolumn{5}{|c|}{ Sleep duration (hours) } \\
\hline & $<5.5$ & $5.5-6.4$ & $6.5-7.4$ & $7.5-8.4$ & $\geq 8.5$ \\
\hline & $(n=114)$ & $(n=264)$ & $(n=390)$ & $(n=213)$ & $(n=79)$ \\
\hline Crude mean, mm (95\%CI) & $0.85(0.82-0.89)$ & $0.83(0.81-0.85)$ & $0.85(0.83-0.87)$ & $0.88(0.86-0.91)$ & $0.90(0.85-0.94)$ \\
\hline Difference $(95 \% \mathrm{CI})$ & $0.00(-0.02-0.02)$ & $-0.02(-0.03--0.02)$ & Reference & $0.03(0.02-0.04)$ & $0.05(0.02-0.07)$ \\
\hline Age-adjusted mean, mm (95\%CI) & $0.87(0.84-0.90)$ & $0.86(0.83-0.88)$ & $0.86(0.84-0.87)$ & $0.86(0.83-0.88)$ & $0.84(0.80-0.88)$ \\
\hline Difference $(95 \% \mathrm{CI})$ & $0.02(0.00-0.03)$ & $0.00(0.00-0.00)$ & Reference & $0.00(-0.01-0.01)$ & $-0.01(-0.04-0.01)$ \\
\hline Multivariable-adjusted mean, $\mathrm{mm}(95 \% \mathrm{CI})(\operatorname{model} 1)^{*}$ & $0.87(0.84-0.90)$ & $0.85(0.83-0.87)$ & $0.85(0.84-0.87)$ & $0.86(0.83-0.88)$ & $0.85(0.81-0.89)$ \\
\hline Difference $(95 \% \mathrm{CI})$ & $0.02(0.00-0.03)$ & $0.00(-0.01-0.00)$ & Reference & $0.00(0.00-0.01)$ & $0.00(-0.02-0.02)$ \\
\hline Multivariable-adjusted mean, $\mathrm{mm}(95 \% \mathrm{CI})(\operatorname{model} 2)^{\dagger}$ & $0.87(0.84-0.90)$ & $0.85(0.83-0.87)$ & $0.85(0.84-0.87)$ & $0.86(0.83-0.88)$ & $0.85(0.81-0.89)$ \\
\hline Difference $(95 \% \mathrm{CI})$ & $0.01(0.00-0.03)$ & $0.00(-0.01-0.00)$ & Reference & $0.00(-0.01-0.01)$ & $0.00(-0.03-0.02)$ \\
\hline
\end{tabular}

Medical Science, Otsu, Shiga), Akihiko Shiino (Biomedical MR Science Center, Shiga University of Medical Science, Otsu, Shiga), Isao Araki (Kusatsu Public Health Center, Kusatsu, Shiga), Teruhiko Tsuru (Department of Urology, Shiga University of Medical Science, Otsu, Shiga), Ikuo Toyama (Unit for Neuropathology and Diagnostics, Molecular Neuroscience Research Center, Shiga University of Medical Science, Otsu, Shiga), Hisakazu Ogita, Souichi Kurita (Division of Medical Biochemistry, Department of Biochemistry and Molecular Biology, Shiga University of Medical Science, Otsu, Shiga), Toshinaga Maeda (Central Research Laboratory, Shiga University of Medical Science, Otsu, Shiga), Naomi Miyamatsu (Department of Clinical Nursing, Shiga University of Medical Science, Otsu, Shiga), Toru Kita (Kobe City Medical Center General Hospital, Kobe, Hyogo), Takeshi Kimura (Department of Cardiovascular Medicine, Kyoto University, Kyoto), Yoshihiko Nishio (Department of Diabetes, Metabolism, and Endocrinology, Kagoshima University, Kagoshima), Yasuyuki Nakamura (Department of Food Science and Human Nutrition, Faculty of Agriculture, Ryukoku University, Otsu, Shiga), Tomonori Okamura (Department of Preventive Medicine and Public Health, School of Medicine, Keio University, Tokyo), Akira Sekikawa, Emma JM Barinas-Mitchell (Department of Epidemiology, Graduate School of Public Health, University of Pittsburgh, Pittsburgh, PA, USA), Daniel Edmundowicz (Department of Medicine, Section of Cardiology, School of Medicine, Temple University, Philadelphia, PA, USA), Takayoshi Ohkubo (Department of Hygiene and Public Health, Teikyo University School of Medicine, Tokyo), Atsushi Hozawa (Preventive Medicine, Epide- miology Section, Tohoku University, Tohoku Medical Megabank Organization, Sendai, Miyagi), Nagako Okuda (Department of Health and Nutrition, University of Human Arts and Sciences, Saitama), Aya Higashiyama (Research and Development Initiative Center, National Cerebral and Cardiovascular Center, Suita, Osaka), Shinya Nagasawa (Department of Epidemiology and Public Health, Kanazawa Medical University, Kanazawa, Ishikawa), Yoshikuni Kita (Faculty of Nursing Science, Tsuruga Nursing University, Tsuruga, Fukui), Yoshitaka Murakami (Division of Medical Statistics, Department of Social Medicine, Toho University, Tokyo), Aya Kadota (Center for Epidemiologic Research in Asia, Department of Public Health, Shiga University of Medical Science, Otsu, Shiga), Akira Fujiyoshi, Naoyuki Takashima, Takashi Kadowaki, Sayaka Kadowaki (Department of Public Health, Shiga University of Medical Science, Otsu, Shiga), Robert D. Abbott, Seiko Ohno (Center for Epidemiologic Research in Asia, Shiga University of Medical Science, Otsu, Shiga), Hisatomi Arima (Department of Preventive Medicine and Public Health, Faculty of Medicine, Fukuoka University, Fukuoka), Takashi Hisamatsu (Department of Environmental Medicine and Public Health, Faculty of Medicine, Shimane University, Izumo, Shimane), Naoko Miyagawa, Keiko Kondo, Sayuki Torii, Yoshino Saito, Maryam Zaid, Sentaro Suzuki, Takahiro Ito, Masahiro Yamazoe, Takeshi Shibukawa, and Masaki Sumi (Department of Public Health, Shiga University of Medical Science, Otsu, Shiga).

\section{Notice of Grant Support}

This work was supported by the Ministry of Edu- 
cation, Culture, Sports, Science and Technology, Japan (Grants-in-Aid for Scientific Research: (A) 13307016; (A) 17209023; (A) 21249043; (A) 23249036; (A) 25253046; (A) 15H02528; and (B) 15H04773), and by GlaxoSmithKlein (grant R01HL068200).

\section{COI}

The authors declare no potential conflicts of interest with regard to this manuscript.

\section{References}

1) Lozano R, Naghavi M, Foreman K, Lim S, Shibuya K, Aboyans V, Abraham J, Adair T, Aggarwal R, Ahn SY, Alvarado M, Anderson HR, Anderson LM, Andrews KG, Atkinson C, Baddour LM, Barker-Collo S, Bartels DH, Bell ML, Benjamin EJ, Bennett D, Bhalla K, Bikbov B, Bin Abdulhak A, Birbeck G, Blyth F, Bolliger I, Boufous S, Bucello C, Burch M, Burney P, Carapetis J, Chen H, Chou D, Chugh SS, Coffeng LE, Colan SD, Colquhoun $\mathrm{S}$, Colson KE, Condon J, Connor MD, Cooper LT, Corriere M, Cortinovis M, de Vaccaro KC, Couser W, Cowie BC, Criqui MH, Cross M, Dabhadkar KC, Dahodwala N, De Leo D, Degenhardt L, Delossantos A, Denenberg J, Des Jarlais DC, Dharmaratne SD, Dorsey ER, Driscoll T, Duber H, Ebel B, Erwin PJ, Espindola P, Ezzati M, Feigin $\mathrm{V}$, Flaxman $\mathrm{AD}$, Forouzanfar $\mathrm{MH}$, Fowkes $\mathrm{FG}$, Franklin R, Fransen M, Freeman MK, Gabriel SE, Gakidou E, Gaspari F, Gillum RF, Gonzalez-Medina D, Halasa YA, Haring D, Harrison JE, Havmoeller R, Hay RJ, Hoen B, Hotez PJ, Hoy D, Jacobsen KH, James SL, Jasrasaria R, Jayaraman S, Johns N, Karthikeyan G, Kassebaum N, Keren A, Khoo JP, Knowlton LM, Kobusingye O, Koranteng A, Krishnamurthi R, Lipnick M, Lipshultz SE, Ohno SL, Mabweijano J, MacIntyre MF, Mallinger L, March L, Marks GB, Marks R, Matsumori A, Matzopoulos R, Mayosi BM, McAnulty JH, McDermott MM, McGrath J, Mensah GA, Merriman TR, Michaud C, Miller M, Miller TR, Mock C, Mocumbi AO, Mokdad AA, Moran A, Mulholland K, Nair MN, Naldi L, Narayan KM, Nasseri K, Norman P, O'Donnell M, Omer SB, Ortblad K, Osborne R, Ozgediz D, Pahari B, Pandian JD, Rivero AP, Padilla RP, Perez-Ruiz F, Perico N, Phillips D, Pierce K, Pope CA, 3rd, Porrini E, Pourmalek F, Raju M, Ranganathan D, Rehm JT, Rein DB, Remuzzi G, Rivara FP, Roberts T, De Leon FR, Rosenfeld LC, Rushton L, Sacco RL, Salomon JA, Sampson U, Sanman E, Schwebel DC, Segui-Gomez M, Shepard DS, Singh D, Singleton J, Sliwa K, Smith E, Steer A, Taylor JA, Thomas B, Tleyjeh IM, Towbin JA, Truelsen T, Undurraga EA, Venketasubramanian N, Vijayakumar L, Vos T, Wagner GR, Wang M, Wang W, Watt K, Weinstock MA, Weintraub R, Wilkinson JD, Woolf AD, Wulf S, Yeh PH, Yip P, Zabetian A, Zheng ZJ, Lopez AD, Murray CJ, AlMazroa MA and Memish ZA: Global and regional mortality from 235 causes of death for 20 age groups in 1990 and 2010: a systematic analysis for the Global Burden of Disease Study 2010. Lancet, 2012; 380: 2095-2128
2) Murray CJ and Lopez AD: Mortality by cause for eight regions of the world: Global Burden of Disease Study. Lancet, 1997; 349: 1269-1276

3) Murray CJ, Vos T, Lozano R, Naghavi M, Flaxman AD, Michaud C, Ezzati M, Shibuya K, Salomon JA, Abdalla S, Aboyans V, Abraham J, Ackerman I, Aggarwal R, Ahn SY, Ali MK, Alvarado M, Anderson HR, Anderson LM, Andrews KG, Atkinson C, Baddour LM, Bahalim AN, Barker-Collo S, Barrero LH, Bartels DH, Basanez MG, Baxter A, Bell ML, Benjamin EJ, Bennett D, Bernabe E, Bhalla K, Bhandari B, Bikbov B, Bin Abdulhak A, Birbeck G, Black JA, Blencowe H, Blore JD, Blyth F, Bolliger I, Bonaventure A, Boufous S, Bourne R, Boussinesq M, Braithwaite T, Brayne C, Bridgett L, Brooker S, Brooks P, Brugha TS, Bryan-Hancock C, Bucello C, Buchbinder R, Buckle G, Budke CM, Burch M, Burney P, Burstein R, Calabria B, Campbell B, Canter CE, Carabin $\mathrm{H}$, Carapetis J, Carmona L, Cella C, Charlson F, Chen H, Cheng AT, Chou D, Chugh SS, Coffeng LE, Colan SD, Colquhoun S, Colson KE, Condon J, Connor MD, Cooper LT, Corriere M, Cortinovis M, de Vaccaro KC, Couser W, Cowie BC, Criqui MH, Cross M, Dabhadkar KC, Dahiya M, Dahodwala N, Damsere-Derry J, Danaei G, Davis A, De Leo D, Degenhardt L, Dellavalle R, Delossantos A, Denenberg J, Derrett S, Des Jarlais DC, Dharmaratne SD, Dherani M, Diaz-Torne C, Dolk H, Dorsey ER, Driscoll T, Duber H, Ebel B, Edmond K, Elbaz A, Ali SE, Erskine H, Erwin PJ, Espindola P, Ewoigbokhan SE, Farzadfar F, Feigin V, Felson DT, Ferrari A, Ferri CP, Fevre EM, Finucane MM, Flaxman S, Flood L, Foreman K, Forouzanfar MH, Fowkes FG, Fransen M, Freeman MK, Gabbe BJ, Gabriel SE, Gakidou E, Ganatra HA, Garcia B, Gaspari F, Gillum RF, Gmel G, Gonzalez-Medina D, Gosselin R, Grainger R, Grant B, Groeger J, Guillemin F, Gunnell D, Gupta R, Haagsma J, Hagan H, Halasa YA, Hall W, Haring D, Haro JM, Harrison JE, Havmoeller R, Hay RJ, Higashi $\mathrm{H}$, Hill C, Hoen B, Hoffman H, Hotez PJ, Hoy D, Huang JJ, Ibeanusi SE, Jacobsen KH, James SL, Jarvis D, Jasrasaria R, Jayaraman S, Johns N, Jonas JB, Karthikeyan G, Kassebaum N, Kawakami N, Keren A, Khoo JP, King CH, Knowlton LM, Kobusingye O, Koranteng A, Krishnamurthi R, Laden F, Lalloo R, Laslett LL, Lathlean T, Leasher JL, Lee YY, Leigh J, Levinson D, Lim SS, Limb E, Lin JK, Lipnick M, Lipshultz SE, Liu W, Loane M, Ohno SL, Lyons R, Mabweijano J, MacIntyre MF, Malekzadeh R, Mallinger L, Manivannan S, Marcenes W, March L, Margolis DJ, Marks GB, Marks R, Matsumori A, Matzopoulos R, Mayosi BM, McAnulty JH, McDermott MM, McGill N, McGrath J, Medina-Mora ME, Meltzer M, Mensah GA, Merriman TR, Meyer AC, Miglioli V, Miller M, Miller TR, Mitchell PB, Mock C, Mocumbi AO, Moffitt TE, Mokdad AA, Monasta L, Montico M, Moradi-Lakeh M, Moran A, Morawska L, Mori R, Murdoch ME, Mwaniki MK, Naidoo K, Nair MN, Naldi L, Narayan KM, Nelson PK, Nelson RG, Nevitt MC, Newton CR, Nolte S, Norman P, Norman R, O'Donnell M, O'Hanlon S, Olives C, Omer SB, Ortblad K, Osborne R, Ozgediz D, Page A, Pahari B, Pandian JD, Rivero AP, Patten SB, Pearce N, Padilla RP, Perez-Ruiz F, Perico N, Pesudovs K, Phillips D, Phillips MR, Pierce K, Pion S, 
Polanczyk GV, Polinder S, Pope CA, 3rd, Popova S, Porrini E, Pourmalek F, Prince M, Pullan RL, Ramaiah KD, Ranganathan D, Razavi H, Regan M, Rehm JT, Rein DB, Remuzzi G, Richardson K, Rivara FP, Roberts T, Robinson C, De Leon FR, Ronfani L, Room R, Rosenfeld LC, Rushton L, Sacco RL, Saha S, Sampson U, Sanchez-Riera L, Sanman E, Schwebel DC, Scott JG, Segui-Gomez M, Shahraz S, Shepard DS, Shin H, Shivakoti R, Singh D, Singh GM, Singh JA, Singleton J, Sleet DA, Sliwa K, Smith E, Smith JL, Stapelberg NJ, Steer A, Steiner T, Stolk WA, Stovner LJ, Sudfeld C, Syed S, Tamburlini G, Tavakkoli M, Taylor HR, Taylor JA, Taylor WJ, Thomas B, Thomson WM, Thurston GD, Tleyjeh IM, Tonelli M, Towbin JA, Truelsen T, Tsilimbaris MK, Ubeda C, Undurraga EA, van der Werf MJ, van Os J, Vavilala MS, Venketasubramanian $\mathrm{N}$, Wang $\mathrm{M}$, Wang W, Watt K, Weatherall DJ, Weinstock MA, Weintraub R, Weisskopf MG, Weissman MM, White RA, Whiteford H, Wiebe N, Wiersma ST, Wilkinson JD, Williams HC, Williams SR, Witt E, Wolfe F, Woolf AD, Wulf S, Yeh PH, Zaidi AK, Zheng ZJ, Zonies D, Lopez AD, AlMazroa MA and Memish ZA: Disability-adjusted life years (DALYs) for 291 diseases and injuries in 21 regions, 1990-2010: a systematic analysis for the Global Burden of Disease Study 2010. Lancet, 2012; 380: 2197-2223

4) Ueshima H, Sekikawa A, Miura K, Turin TC, Takashima N, Kita Y, Watanabe M, Kadota A, Okuda N, Kadowaki T, Nakamura Y and Okamura T: Cardiovascular disease and risk factors in Asia: a selected review. Circulation, 2008; 118: 2702-2709

5) Rumana N, Kita Y, Turin TC, Murakami Y, Sugihara H, Morita Y, Tomioka N, Okayama A, Nakamura Y, Abbott $\mathrm{RD}$ and Ueshima $\mathrm{H}$ : Trend of increase in the incidence of acute myocardial infarction in a Japanese population: Takashima AMI Registry, 1990-2001. Am J Epidemiol, 2008; 167: 1358-1364

6) Partinen M, Putkonen PT, Kaprio J, Koskenvuo M and Hilakivi I: Sleep disorders in relation to coronary heart disease. Acta Med Scand Suppl, 1982; 660: 69-83

7) Cappuccio FP, Cooper D, D'Elia L, Strazzullo P and Miller MA: Sleep duration predicts cardiovascular outcomes: a systematic review and meta-analysis of prospective studies. Eur Heart J, 2011; 32: 1484-1492

8) Ayas NT, White DP, Manson JE, Stampfer MJ, Speizer FE, Malhotra A and Hu FB: A prospective study of sleep duration and coronary heart disease in women. Arch Intern Med, 2003; 163: 205-209

9) Ikehara S, Iso H, Date C, Kikuchi S, Watanabe Y, Wada Y, Inaba Y, Tamakoshi A and Group JS: Association of sleep duration with mortality from cardiovascular disease and other causes for Japanese men and women: the JACC study. Sleep, 2009; 32: 295-301

10) Sabanayagam $C$ and Shankar A: Sleep duration and cardiovascular disease: results from the National Health Interview Survey. Sleep, 2010; 33: 1037-1042

11) Chandola T, Ferrie JE, Perski A, Akbaraly T and Marmot MG: The effect of short sleep duration on coronary heart disease risk is greatest among those with sleep disturbance: a prospective study from the Whitehall II cohort. Sleep, 2010; 33: 739-744

12) Shankar A, Koh WP, Yuan JM, Lee HP and Yu MC: Sleep duration and coronary heart disease mortality among Chinese adults in Singapore: a population-based cohort study. Am J Epidemiol, 2008; 168: 1367-1373

13) Gangwisch JE, Heymsfield SB, Boden-Albala B, Buijs RM, Kreier F, Pickering TG, Rundle AG, Zammit GK and Malaspina D: Short sleep duration as a risk factor for hypertension: analyses of the first National Health and Nutrition Examination Survey. Hypertension, 2006; 47: 833-839

14) Tasali E, Leproult R and Spiegel K: Reduced sleep duration or quality: relationships with insulin resistance and type 2 diabetes. Prog Cardiovasc Dis, 2009; 51: 381-391

15) Vgontzas AN, Zoumakis E, Bixler EO, Lin HM, Follett $\mathrm{H}$, Kales A and Chrousos GP: Adverse effects of modest sleep restriction on sleepiness, performance, and inflammatory cytokines. J Clin Endocrinol Metab, 2004; 89: 2119-2126

16) Dowd JB, Goldman N and Weinstein M: Sleep duration, sleep quality, and biomarkers of inflammation in a Taiwanese population. Ann Epidemiol, 2011; 21: 799-806

17) Matthews KA, Everson-Rose SA, Kravitz HM, Lee L, Janssen I and Sutton-Tyrrell K: Do reports of sleep disturbance relate to coronary and aortic calcification in healthy middle-aged women?: Study of women's health across the nation. Sleep Med, 2013; 14: 282-287

18) King CR, Knutson KL, Rathouz PJ, Sidney S, Liu K and Lauderdale DS: Short sleep duration and incident coronary artery calcification. JAMA, 2008; 300: 2859-2866

19) Wolff B, Volzke H, Schwahn C, Robinson D, Kessler C and John U: Relation of self-reported sleep duration with carotid intima-media thickness in a general population sample. Atherosclerosis, 2008; 196: 727-732

20) Ma CC, Burchfiel CM, Charles LE, Dorn JM, Andrew ME, Gu JK, Joseph PN, Fekedulegn D, Slaven JE, Hartley TA, Mnatsakanova A and Violanti JM: Associations of objectively measured and self-reported sleep duration with carotid artery intima media thickness among police officers. Am J Ind Med, 2013; 56: 1341-1351

21) Sands MR, Lauderdale DS, Liu K, Knutson KL, Matthews KA, Eaton CB, Linkletter CD and Loucks EB: Short sleep duration is associated with carotid intimamedia thickness among men in the Coronary Artery Risk Development in Young Adults (CARDIA) Study. Stroke, 2012; 43: 2858-2864

22) Matthews KA, Strollo PJ, Jr., Hall M, Mezick EJ, Kamarck TW, Owens JF, Buysse DJ and Reis SE: Associations of Framingham risk score profile and coronary artery calcification with sleep characteristics in middle-aged men and women: Pittsburgh SleepSCORE study. Sleep, 2011; 34: 711-716

23) Kim CW, Chang Y, Zhao D, Cainzos-Achirica M, Ryu S, Jung HS, Yun KE, Choi Y, Ahn J, Zhang Y, Rampal S, Baek Y, Lima JA, Shin H, Guallar E, Cho J and Sung E: Sleep Duration, Sleep Quality, and Markers of Subclinical Arterial Disease in Healthy Men and Women. Arterioscler Thromb Vasc Biol, 2015; 35: 2238-2245

24) Abe T, Aoki T, Yata $S$ and Okada M: Sleep duration is significantly associated with carotid artery atherosclerosis incidence in a Japanese population. Atherosclerosis, 2011; 217: 509-513

25) Zaid M, Fujiyoshi A, Kadota A, Abbott RD and Miura K: 
Coronary Artery Calcium and Carotid Artery Intima Media Thickness and Plaque: Clinical Use in Need of Clarification. J Atheroscler Thromb, 2017; 24: 227-239

26) Nezu T, Hosomi N, Aoki $S$ and Matsumoto M: Carotid Intima-Media Thickness for Atherosclerosis. J Atheroscler Thromb, 2016; 23: 18-31

27) Ueshima H, Kadowaki T, Hisamatsu T, Fujiyoshi A, Miura K, Ohkubo T, Sekikawa A, Kadota A, Kadowaki S, Nakamura Y, Miyagawa N, Okamura T, Kita Y, Takashima N, Kashiwagi A, Maegawa H, Horie M, Yamamoto T, Kimura T, Kita T, Access and Groups SR: Lipoprotein-associated phospholipase A2 is related to risk of subclinical atherosclerosis but is not supported by Mendelian randomization analysis in a general Japanese population. Atherosclerosis, 2016; 246: 141-147

28) Radloff LS: The CES-D scale: A self-report depression scale for research in the general population. Appl Psychol Meas, 1977; 1: 385-401

29) Kashiwagi A, Kasuga M, Araki E, Oka Y, Hanafusa T, Ito H, Tominaga M, Oikawa S, Noda M, Kawamura T, Sanke T, Namba M, Hashiramoto M, Sasahara T, Nishio Y, Kuwa K, Ueki K, Takei I, Umemoto M, Murakami M, Yamakado M, Yatomi Y, Ohashi $\mathrm{H}$ and Committee on the Standardization of Diabetes Mellitus-Related Laboratory Testing of Japan Diabetes S: International clinical harmonization of glycated hemoglobin in Japan: From Japan Diabetes Society to National Glycohemoglobin Standardization Program values. J Diabetes Investig, 2012; 3: 39-40

30) Nakamura M, Sato $S$ and Shimamoto T: Improvement in Japanese clinical laboratory measurements of total cholesterol and HDL-cholesterol by the US Cholesterol Reference Method Laboratory Network. J Atheroscler Thromb, 2003; 10: 145-153

31) Hisamatsu T, Fujiyoshi A, Miura K, Ohkubo T, Kadota A, Kadowaki S, Kadowaki T, Yamamoto T, Miyagawa N, Zaid M, Torii S, Takashima N, Murakami Y, Okamura T, Horie M, Ueshima H and Group SR: Lipoprotein particle profiles compared with standard lipids in association with coronary artery calcification in the general Japanese population. Atherosclerosis, 2014; 236: 237-243

32) Agatston AS, Janowitz WR, Hildner FJ, Zusmer NR, Viamonte M, Jr. and Detrano R: Quantification of coronary artery calcium using ultrafast computed tomography. J Am Coll Cardiol, 1990; 15: 827-832

33) Sekikawa A, Curb JD, Edmundowicz D, Okamura T, Choo J, Fujiyoshi A, Masaki K, Miura K, Kuller LH, Shin $\mathrm{C}$ and Ueshima H: Coronary artery calcification by computed tomography in epidemiologic research and cardiovascular disease prevention. J Epidemiol, 2012; 22: 188-198

34) Sekikawa A, Ueshima H, Kadowaki T, El-Saed A, Okamura T, Takamiya T, Kashiwagi A, Edmundowicz D, Murata K, Sutton-Tyrrell K, Maegawa H, Evans RW, Kita $\mathrm{Y}$ and Kuller LH: Less subclinical atherosclerosis in Japanese men in Japan than in White men in the United States in the post-World War II birth cohort. Am J Epidemiol, 2007; 165: 617-624

35) Abbott RD, Ueshima H, Rodriguez BL, Kadowaki T, Masaki KH, Willcox BJ, Sekikawa A, Kuller LH, Edmundowicz D, Shin C, Kashiwagi A, Nakamura Y, El-Saed A, Okamura T, White R and Curb JD: Coronary artery calcification in Japanese men in Japan and Hawaii. Am J Epidemiol, 2007; 166: 1280-1287

36) Kadota A, Miura K, Okamura T, Fujiyoshi A, Ohkubo T, Kadowaki T, Takashima N, Hisamatsu T, Nakamura Y, Kasagi F, Maegawa H, Kashiwagi A, Ueshima H, Group SR and Group NDR: Carotid intima-media thickness and plaque in apparently healthy Japanese individuals with an estimated 10-year absolute risk of CAD death according to the Japan Atherosclerosis Society (JAS) guidelines 2012: the Shiga Epidemiological Study of Subclinical Atherosclerosis (SESSA). J Atheroscler Thromb, 2013; 20: 755-766

37) Sutton-Tyrrell K, Wolfson SK, Jr., Thompson T and Kelsey SF: Measurement variability in duplex scan assessment of carotid atherosclerosis. Stroke, 1992; 23: 215 220

38) St-Onge MP, Grandner MA, Brown D, Conroy MB, Jean-Louis G, Coons M, Bhatt DL, American Heart Association Obesity BCD, Nutrition Committees of the Council on L, Cardiometabolic H, Council on Cardiovascular Disease in the $\mathrm{Y}$, Council on Clinical $\mathrm{C}$ and Stroke C: Sleep Duration and Quality: Impact on Lifestyle Behaviors and Cardiometabolic Health: A Scientific Statement From the American Heart Association. Circulation, 2016; 134: e367-e386

39) Kaneita Y, Uchiyama M, Yoshiike N and Ohida T: Associations of usual sleep duration with serum lipid and lipoprotein levels. Sleep, 2008; 31: 645-652

40) Aziz M, Ali SS, Das S, Younus A, Malik R, Latif MA, Humayun C, Anugula D, Abbas G, Salami J, Elizondo JV, Veledar E and Nasir K: Association of Subjective and Objective Sleep Duration as well as Sleep Quality with Non-Invasive Markers of Sub-Clinical Cardiovascular Disease (CVD): A Systematic Review. J Atheroscler Thromb, 2017; 24: 208-226 
Supplementary Table 1. Prevalence and odds ratios of coronary artery calcification* among male participants without prior stroke or myocardial infarction in SESSA (2006-2008) stratified by sleep duration $(n=1027)$

\begin{tabular}{lccccc}
\hline & \multicolumn{4}{c}{ Sleep duration (hours) } \\
\cline { 2 - 6 } & $(n=106)$ & $(n=262)$ & $(n=375)$ & $(n=211)$ & $(n=73)$ \\
\hline CAC, n (\%) & $50(47.2)$ & $109(41.6)$ & $184(49.1)$ & $99(46.9)$ & $43(58.9)$ \\
Crude OR (95\%CI) & $0.93(0.60-1.43)$ & $0.74(0.54-1.02)$ & 1.00 & $0.92(0.66-1.29)$ & $1.49(0.90-2.47)$ \\
Age-adjusted OR (95\%CI) & $1.08(0.67-1.74)$ & $0.84(0.59-1.18)$ & 1.00 & $0.71(0.50-1.02)$ & $0.94(0.55-1.61)$ \\
Multivariable-adjusted OR (95\%CI) (model 1) $^{\dagger}$ & $1.09(0.67-1.77)$ & $0.81(0.57-1.15)$ & 1.00 & $0.68(0.47-0.99)$ & $1.00(0.58-1.75)$ \\
Multivariable-adjusted OR (95\%CI) (model 2) & $1.03(0.63-1.70)$ & $0.83(0.58-1.18)$ & 1.00 & $0.66(0.45-0.96)$ & $0.94(0.53-1.67)$ \\
\hline
\end{tabular}

* Defined as coronary artery calcification score $\geq 10$.

${ }^{\dagger}$ Adjusted for age, body mass index, smoking status, regular exercise, alcohol consumption, and types of computed tomography scan

*Adjusted for age, body mass index, smoking status, regular exercise, alcohol consumption, types of computed tomography scan, systolic blood pressure, total cholesterol, high density lipoprotein cholesterol, hemoglobin A1c, and medication status

CAC: coronary artery calcification; CI: confidence interval; OR: odds ratio; SESSA: Shiga Epidemiological Study of Subclinical Atherosclerosis

Supplementary Table 2. Prevalence and odds ratios of coronary artery calcification (defined as coronary artery calcification score $>0)$ among male participants in SESSA (2006-2008) stratified by sleep duration $(n=1093)$

\begin{tabular}{lccccc}
\hline & \multicolumn{4}{c}{ Sleep duration (hours) } \\
\cline { 2 - 6 } & $(n=118)$ & $(n=278)$ & $(n=394)$ & $(n=223)$ & $(n=80)$ \\
\hline CAC, n (\%) & $82(69.5)$ & $170(61.2)$ & $257(65.2)$ & $150(67.3)$ & $58(72.5)$ \\
Crude OR (95\%CI) & $1.21(0.78-1.89)$ & $0.84(0.61-1.15)$ & 1.00 & $1.10(0.77-1.55)$ & $1.41(0.83-2.39)$ \\
Age-adjusted OR (95\%CI) & $1.52(0.93-2.50)$ & $1.02(0.72-1.45)$ & 1.00 & $0.81(0.56-1.18)$ & $0.79(0.45-1.40)$ \\
Multivariable-adjusted OR (95\%CI) (model 1) $^{*}$ & $1.72(1.00-2.95)$ & $1.03(0.71-1.51)$ & 1.00 & $0.78(0.52-1.15)$ & $0.99(0.54-1.81)$ \\
Multivariable-adjusted OR (95\%CI) (model 2) $^{\dagger}$ & $1.63(0.94-2.80)$ & $1.03(0.70-1.52)$ & 1.00 & $0.75(0.50-1.11)$ & $0.95(0.52-1.76)$ \\
\hline
\end{tabular}

*Adjusted for age, body mass index, smoking status, regular exercise, alcohol consumption, and types of computed tomography scan

${ }^{\dagger}$ Adjusted for age, body mass index, smoking status, regular exercise, alcohol consumption, types of computed tomography scan, systolic blood pressure, total cholesterol, high density lipoprotein cholesterol, hemoglobin A1c, and medication status

CAC: coronary artery calcification; CI: confidence interval; OR: odds ratio; SESSA: Shiga Epidemiological Study of Subclinical Atherosclerosis 
Supplementary Table 3. Odds ratios of coronary artery calcification * among selected subgroups of men enrolled in SESSA (20062008) stratified by sleep duration $(n=1093)$

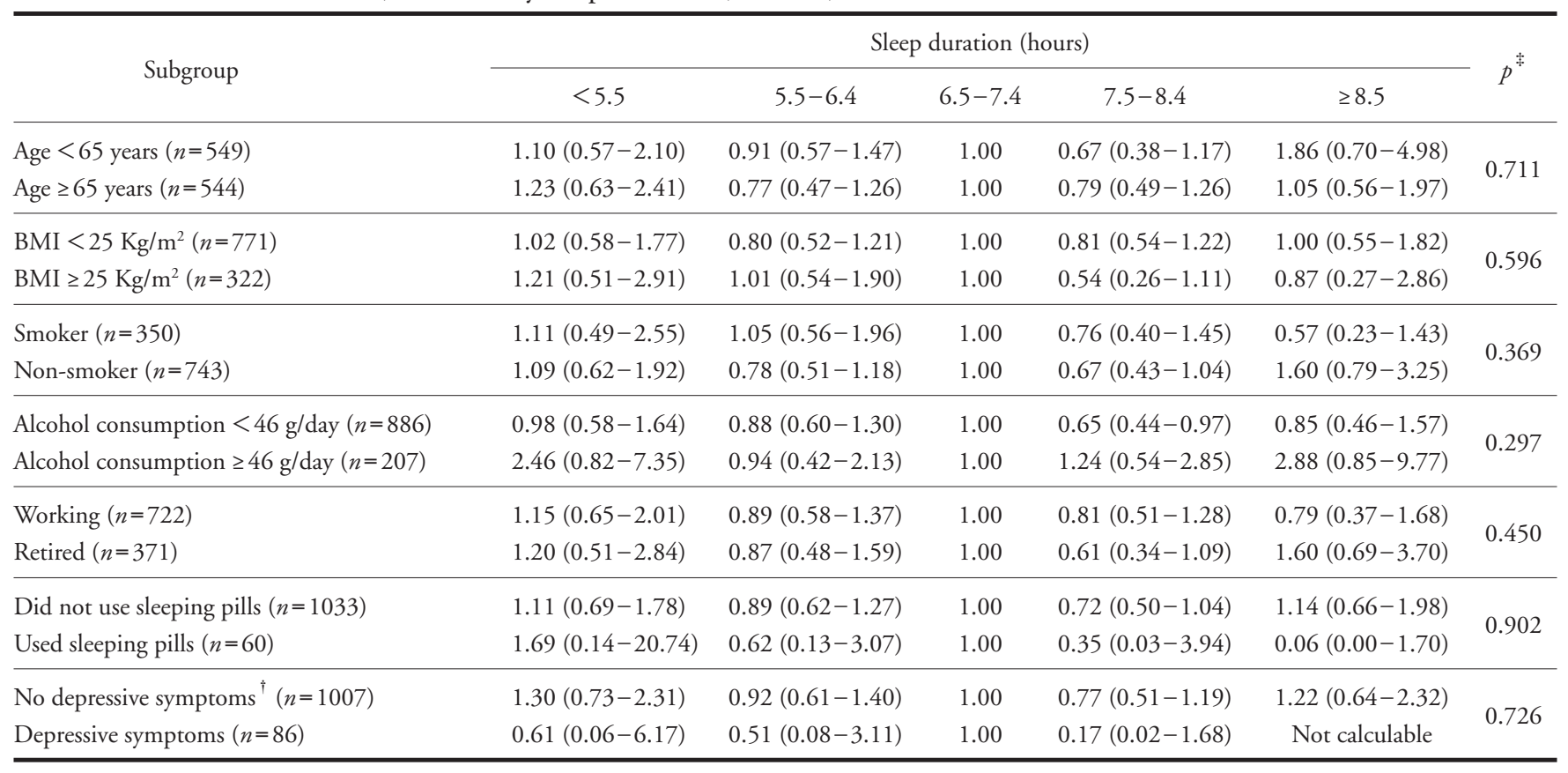

Model adjusted for age, body mass index, smoking status, regular exercise, alcohol consumption, and types of computed tomography scan except for each stratified variable.

* Defined as coronary artery calcification score $\geq 10$.

${ }^{\dagger}$ Center for Epidemiologic Studies Depression Scale score $\geq 16$

\$Test for heterogeneity

CI: confidence interval; OR: odds ratio; SESSA: Shiga Epidemiological Study of Subclinical Atherosclerosis 
Supplementary Table 4. Mean IMT in selected subgroups of men enrolled SESSA (2006-2008) stratified by sleep duration $(n=1060)$

\begin{tabular}{|c|c|c|c|c|c|c|}
\hline Subgroup & \multicolumn{5}{|c|}{ Sleep duration (hours) } & $p^{\dagger}$ \\
\hline Age $\geq 65$ years $(n=529)$ & $0.96(0.90-1.02)$ & $0.93(0.89-0.97)$ & $0.92(0.89-0.95)$ & $0.94(0.90-0.97)$ & $0.94(0.88-0.99)$ & 0.612 \\
\hline $\mathrm{BMI}<25 \mathrm{Kg} / \mathrm{m}^{2}(n=752)$ & $0.85(0.81-0.89)$ & $0.84(0.82-0.87)$ & $0.84(0.82-0.86)$ & $0.84(0.82-0.87)$ & $0.84(0.80-0.89)$ & 0.776 \\
\hline Non-smoker $(n=724)$ & $0.88(0.84-0.92)$ & $0.86(0.84-0.89)$ & $0.87(0.85-0.89)$ & $0.87(0.84-0.90)$ & $0.86(0.81-0.91)$ & 0.94 \\
\hline Alcohol consumption $<46 \mathrm{~g} /$ day $(n=862)$ & $0.88(0.85-0.92)$ & $0.86(0.84-0.89)$ & $0.86(0.84-0.88)$ & $0.86(0.83-0.89)$ & $0.83(0.79-0.87)$ & \multirow{2}{*}{0.060} \\
\hline Alcohol consumption $\geq 46 \mathrm{~g} /$ day $(n=198)$ & $0.83(0.75-0.91)$ & $0.80(0.75-0.86)$ & $0.85(0.80-0.90)$ & $0.84(0.78-0.89)$ & $0.90(0.81-0.99)$ & \\
\hline Working $(n=697)$ & $0.84(0.81-0.88)$ & $0.81(0.79-0.84)$ & $0.83(0.81-0.85)$ & $0.82(0.79-0.85)$ & $0.85(0.80-0.90)$ & 0.341 \\
\hline Used sleeping pills $(n=59)$ & $0.86(0.73-0.99)$ & $0.88(0.80-0.97)$ & $0.93(0.84-1.02)$ & $0.91(0.75-1.07)$ & $0.76(0.49-1.04)$ & 0.637 \\
\hline No depressive symptoms ${ }^{*}(n=977)$ & $0.88(0.85-0.92)$ & $0.86(0.83-0.88)$ & $0.86(0.84-0.88)$ & $0.86(0.83-0.88)$ & $0.86(0.82-0.89)$ & \multirow{2}{*}{0.601} \\
\hline Depressive symptoms $*(n=83)$ & $0.78(0.68-0.88)$ & $0.80(0.73-0.86)$ & $0.81(0.73-0.90)$ & $0.83(0.74-0.93)$ & Not calculable & \\
\hline
\end{tabular}

Model adjusted for age, body mass index, smoking status, regular exercise, alcohol consumption, and types of computed tomography scan except for each stratified variable.

* Center for Epidemiologic Studies Depression Scale score $\geq 16$

${ }^{\dagger}$ Test for heterogeneity

CI: confidence interval; IMT: intima media thickness; SESSA: Shiga Epidemiological Study of Subclinical Atherosclerosi

Supplementary Table 5. Summary of the previous studies examining the association between sleep duration and CAC

\begin{tabular}{|c|c|c|c|c|c|c|}
\hline $\begin{array}{l}\text { First Author, } \\
\text { Publication Year }\end{array}$ & Country & Study Design & Participants & Age & $\begin{array}{c}\text { Sleep } \\
\text { Measurement }\end{array}$ & Results \\
\hline $\begin{array}{l}\text { Kim et al. }{ }^{23)}, 2015 \\
\text { (Samsun) }\end{array}$ & Korea & Cross-sectional & $\begin{array}{l}29,203 \text { men } \\
\text { and women }\end{array}$ & Mean 42 & $\begin{array}{l}\text { Self-Report } \\
\text { (PSQI) }\end{array}$ & U-shaped association \\
\hline $\begin{array}{l}\text { Matthews et al. }{ }^{17)}, 2013 \\
\text { (SWAN) }\end{array}$ & USA & Cross-sectional & 512 women & Mean 50 & $\begin{array}{l}\text { Self-Report } \\
\text { (PSQI) }\end{array}$ & No clear association \\
\hline $\begin{array}{l}\text { King et al. }{ }^{18)}, 2008 \\
\text { (CARDIA) }\end{array}$ & USA & $\begin{array}{l}\text { Longitudinal } \\
\text { (5 years) }\end{array}$ & $\begin{array}{l}204 \text { men } \\
291 \text { women }\end{array}$ & Mean 40 & $\begin{array}{l}\text { Self-Report } \\
\text { (PSQI) } \\
\text { Actigraphy }\end{array}$ & $\begin{array}{l}\text { Increased CAC prevalence among } \\
\text { participants with short sleep dura- } \\
\text { tion measured by actigraphy, but } \\
\text { no clear association for self- } \\
\text { reported sleep duration }\end{array}$ \\
\hline
\end{tabular}


Supplementary Table 6. Summary of the previous studies examining the association between sleep duration and carotid IMT

\begin{tabular}{|c|c|c|c|c|c|c|}
\hline $\begin{array}{l}\text { First Author, } \\
\text { Publication Year }\end{array}$ & Country & Study Design & Particitants & Age & $\begin{array}{c}\text { Sleep } \\
\text { Measurement }\end{array}$ & Results \\
\hline $\begin{array}{l}\text { Wolff et al. }{ }^{19)}, 2008 \\
\text { (SHIP) }\end{array}$ & Germany & Cross-sectional & $\begin{array}{l}2,437 \text { men } \\
\text { and women }\end{array}$ & $45-81$ & Self-Report & $\begin{array}{l}\text { Increased carotid IMT among partici- } \\
\text { pants with sleep duration of }<5 \text { hours } \\
\text { and }>9 \text { hours }\end{array}$ \\
\hline Ma et al. ${ }^{20)}, 2013$ & USA & Cross-sectional & $\begin{array}{l}190 \text { men } \\
67 \text { women }\end{array}$ & Mean 42 & $\begin{array}{l}\text { Self-Report } \\
\text { (PSQI) } \\
\text { Actigraphy }\end{array}$ & $\begin{array}{l}\text { U-shaped association for sleep dura- } \\
\text { tion measured by actigraphy, but not } \\
\text { for self-reported sleep duration }\end{array}$ \\
\hline $\begin{array}{l}\text { Sands et al. }{ }^{21)}, 2012 \\
\text { (CARDIA) }\end{array}$ & USA & Cross-sectional & $\begin{array}{l}260 \text { men } \\
357 \text { women }\end{array}$ & $37-52$ & Actigraphy & $\begin{array}{l}\text { Increased carotid IMT in male partici- } \\
\text { pants with longer objective sleep dura- } \\
\text { tion, but not in female participants }\end{array}$ \\
\hline Abe $e t a l .{ }^{24)}, 2011$ & Japan & Cross-sectional & $\begin{array}{l}1064 \text { men } \\
1150 \text { women }\end{array}$ & $40-85$ & Self-Report & $\begin{array}{l}\text { Long sleep duration }(\geq 7 \mathrm{~h}) \text { correlated } \\
\text { with higher incidence of carotid artery } \\
\text { atherosclerosis }\end{array}$ \\
\hline
\end{tabular}

IMT: intima media thickness; PSQI: Pittsburgh Sleep Quality Index 